\title{
Geoprocessamento de Modelos Digitais de Elevação para Mapeamento da Curvatura Horizontal em Microbacias
}

\section{Geoprocessing of Digital Elevation Models for Mapping plan Curvature in Watersheds}

\author{
Márcio de Morisson Valeriano, \\ Osmar Abílio de Carvalho Júnior ${ }^{1}$ \\ 1nstituto Nacional de Pesquisas Espaciais, São José dos Campos, SP, Brasil. valerian@ltid.inpe.br/osmar@ltid.inpe. \\ Tel.: (012)3945-6424, Fax: (012) 3945-6488. \\ ${ }^{2}$ Bolsista do CNPq.
}

\begin{abstract}
RESUMO
Este trabalho tem o objetivo de desenvolver e avaliar um procedimento de análise de Modelos Digitais de Elevação (MDE) com Sistemas de Informação Geográfica (SIG) para mapeamento da curvatura horizontal. O método baseia-se em janelas móveis aplicadas sobre a imagem de orientação de vertentes, derivada do MDE. Os testes envolveram dados de seis microbacias de diferentes tipos de relevo, krigados a partir de curvas de nível de mapas publicados. O cálculo de curvatura horizontal programado demandou a resolução espacial como uma das entradas, de modo a resultar em valores absolutos comparáveis, com diferença de ângulo de azimute por distância horizontal $(/ \mathrm{m})$ como unidade. A sobreposição dos resultados calculados em cada passagem da janela móvel, orientada nas direções dos oito pixels vizinhos em cada posição da janela, foi coordenada em octantes, de acordo com a classe de orientação das vertentes. A interpretação visual de resultados numéricos aliado ao reconhecimento de formas conhecidas de relevo subsidiou o estabelecimento de limiares arbitrários de curvatura para uma classificação das vertentes (convergentes, retilíneas e divergentes).
\end{abstract}

Palavras-chave: geoprocessamento, microbacias, relevo.

\section{ABSTRACT}

This study aims the description and evaluation of a simple approach to map plan curvature from Digital Elevation Models (DEM) with common tools of Geographical Information Systems (GIS). This method is based on the application of a local 3x3 pixel moving window on the aspect image, derived from the DEM. The testes used data kriged from contour lines of published maps of six watersheds from different terrain types. The curvature calculation required the DEM spatial resolution as one of the inputs, so as to calculate a comparable absolute value, with slope azimuth angle per horizontal distance $(/ \mathrm{m})$ as unit. The classification of slope direction in octants was used to control the overlapping of the curvature results, calculated towards the eight neighbor pixels of each windowed position. The placement of boundaries with guidance from visual analysis of known slope forms assisted the establishment of

arbitrary curvature thresholds for the slope curvature classes (convergent, divergent and rectilinear).

Key words: geoprocessing, watershed, relief

\section{Introdução}

Os dados topográficos são fonte de variáveis importantes e freqüentemente solicitadas nas análises ambientais aplicadas a microbacias. Os estudos envolvendo dados topográficos têm se voltado à caracterização de unidades da paisagem com base em variáveis morfológicas, estreitamente ligadas a feições geométricas da superfície sob análise (Doornkamp \& King, 1971; Meijerink, 1988). A disponibilidade crescente de bases topográficas digitais, aliada ao uso de Sistemas de Informação Geográfica (SIG), tem impulsionado o desenvolvimento de métodos automáticos de extração de variáveis topográficas, para posterior tratamento e integração em ambiente computacional. A operação de modelos analíticos com Planos de Informação (PI) sobrepostos em SIG é feita com operações entre os chamados Modelos Digitais do Terreno (MDT), dos quais o Modelo Digital de Elevação (MDE) é um exemplo de evidente utilização.

Em microbacias, predomina o enfoque ao problema da erosão em seus múltiplos aspectos, como estimativas diretas (Castro \& Valério Filho, 1997; Ranieri et al., 1998; Molnár \& Julien, 1998) e mapeamento de fatores envolvidos (Desmet \& 
Govers, 1996; Kinnel, 2001). Dessa linha de pesquisa, depreende-se que diferentes tipos de relevo requerem diferentes métodos de tratamento, como propõem Valeriano \& Garcia (2000), que recomendam uma estratificação do tratamento de dados dentro da escala de trabalho, seja uma unidade geomorfológica, microbacia ou vertente. As diferentes variáveis passíveis de extração automática em SIG podem dar suporte à classificação multivariada da paisagem, fornecendo uma segmentação da mesma em ambientes topográficos. A identificação de unidades de relevo (Meijerink, 1988; Giles \& Franklin, 1998) vêm sendo desenvolvidas em ambiente computacional, amenizando a demanda de trabalho manual e a subjetividade dessas atividades.

Os mecanismos principais de atuação do relevo referem-se à distribuição dos processos hidrológicos e erosivos e da temperatura do solo. Assumindo o desenvolvimento de solos como resposta a estes efeitos, Moore et al. (1993) relacionaram atributos pedológicos a variáveis topográficas. Foi verificado que a situação topográfica explicou cerca de metade da variação do $\mathrm{pH}$, do conteúdo de fósforo e da espessura do horizonte A. Briggs \& Shishiro (1985) mostraram que a variabilidade dos atributos de solo dentro de cada unidade homogênea de relevo apresentou considerável redução e que diferentes intensidades de amostragem devem ser aplicadas ao levantamento de diferentes atributos, bem como em diferentes tipos de terreno. Analogamente, Florinsky \& Kuryakova (1996) consideraram recomendável o uso de modelos digitais e mapas de variáveis topográficas como contribuição ao levantamento e ao mapeamento da vegetação, assim como à compreensão de seus aspectos dinâmicos.

Em estudo de instabilidade de encostas, Fernandes et al. (2001) comentam que a declividade vem sendo utilizada de maneira predominante, ou até exclusiva, como fator condicionante de cunho geomorfológico, gerando, com freqüência, distorções na análise de deslizamentos. $\mathrm{O}$ mesmo pode se dizer dos estudos de processos erosivos e dos métodos de planejamento territorial. A despeito de outras possíveis causas dessa tendência, a disponibilidade de algoritmos de execução expedita para declividade, em detrimento das outras variáveis envolvidas nestes processos, tende a intensificar essa simplificação, sobretudo com a popularização dos sistemas de informação geográfica.

Sob este ponto de vista, a geração e difusão de algoritmos para mapeamento automático de outras variáveis topográficas representa uma necessidade estratégica para a operacionalização de análises digitais adequadas às relações entre fatores topográficos diversos, além de permitir o desenvolvimento de novos modelos mais complexos.

A primeira derivação da superfície é um vetor com duas componentes a declividade e o aspecto. A segunda derivada representa a curvatura da superfície, usualmente, expressa em curvatura vertical (na direção da declividade) e curvatura horizontal (ao longo da curva de nível).

A análise da convexidade do relevo é reconhecida como um atributo importante para a distinção de sítios geomorfológicos, estudada desde os trabalhos de Davis (1892) e Gilbert (1909). A curvatura horizontal refere-se ao caráter divergente/ convergente dos fluxos de matéria sobre o terreno quando analisado em projeção horizontal. Esta variável está relacionada aos processos de migração e acúmulo de água, minerais e matéria orgânica no solo através da superfície, proporcionados pela gravidade, e desempenha papel importante sobre o decorrente balanço hídrico e os processos de pedogênese.

A possibilidade de simular digitalmente métodos de medição da curvatura horizontal é uma perspectiva de grande interesse neste contexto. Este trabalho apresenta uma avaliação de um cálculo de curvatura horizontal de MDE feito em Sistemas de Informação Geográfica (SIG).

\section{Material e Métodos}

Foram selecionadas 6 microbacias (Ribeirão Preto, rios Jacuí, Bangu e Grande Ubatuba e córregos São Joaquim e Soturninha) com diferentes características de relevo, de área total e das especificações cartográficas dos mapas-base. A Tabela 1 resume estas diferenças e as decorrentes características dos arquivos digitais (número de pontos digitalizados e tamanho dos arquivos $D X F$ e $A S C I I$ ) processados para a formação dos MDE.

Tabela 1 Especificações geométricas, relevo predominante e tamanho dos arquivos de isolinhas digitalizadas

\begin{tabular}{|c|c|c|c|c|c|c|}
\hline Arquivo (escala) & $\begin{array}{c}\text { Área } \\
\text { (ha) }\end{array}$ & $\begin{array}{c}{ }^{\mathrm{a}} \text { Eq.v. } \\
\text { (m) }\end{array}$ & Relevo predominante & $\mathrm{n}^{\mathrm{o}}$ pts. & $\begin{array}{c}{ }^{\mathrm{b}} \mathrm{KB} \\
\mathrm{DXF}\end{array}$ & $\begin{array}{c}\text { KB } \\
\text { ASCII }\end{array}$ \\
\hline Folha de Cunha (1:50.000) & 70912 & 25 & Montanhoso & 248.394 & 30.692 & 5.450 \\
\hline Folha de Ubatuba (1:50.000) & 70912 & 25 & Montanhoso a escarpado (+ mar) & 187.629 & 23.202 & 4.048 \\
\hline MB Ribeirão Preto (1:50.000) & 73958 & 20 & Suave ondulado a forte ondulado & 88.862 & 7.632 & 1.892 \\
\hline${ }^{\mathrm{c}}$ MB São Joaquim (1:20.000) & ${ }^{c} 3114$ & 10 & Suave ondulado a ondulado & 11.616 & 1.423 & 248 \\
\hline MB Soturninha (1:10.000) & 2003 & 5 & Suave ondulado & 11.730 & 1.092 & 251 \\
\hline
\end{tabular}

() Eqüidistância vertical entre isolinhas; () tamanho de arquivo dxf quando sob o formato AutoCAD versão 12; () ${ }^{\mathrm{c}}$ apenas isolinhas da MB; os demais arquivos se referem a todo o retângulo envolvente da área indicada 
As seis áreas localizam-se em diferentes unidades geomorfológicas do Estado de São Paulo (Ross \& Moroz, 1997), conforme a Figura 1. No Cinturão Orogênico do Atlântico (unidade morfoetrutural), foram selecionadas as microbacias dos rios Jacuí, Bangu e Grande Ubatuba, áreas de fragilidade e dissecação do relevo altas a muito altas. Da Folha de Cunha, foram preparados os dados das microbacias dos rios Jacuí e Bangu, ambas localizadas sobre a Serra do Mar (Planalto de Paraitinga/Paraibuna) e com relação de vizinhança. A microbacia do rio Jacuí tem como limite a sudeste trecho do topo da escarpa que separa a Serra do Mar da Planície Litorânea. Selecionada da folha de Ubatuba, a microbacia do rio Grande Ubatuba engloba a própria escarpa, estendendo-se até o mar através da Planície Litorânea, num grande intervalo altimétrico, de cerca de $1000 \mathrm{~m}$.

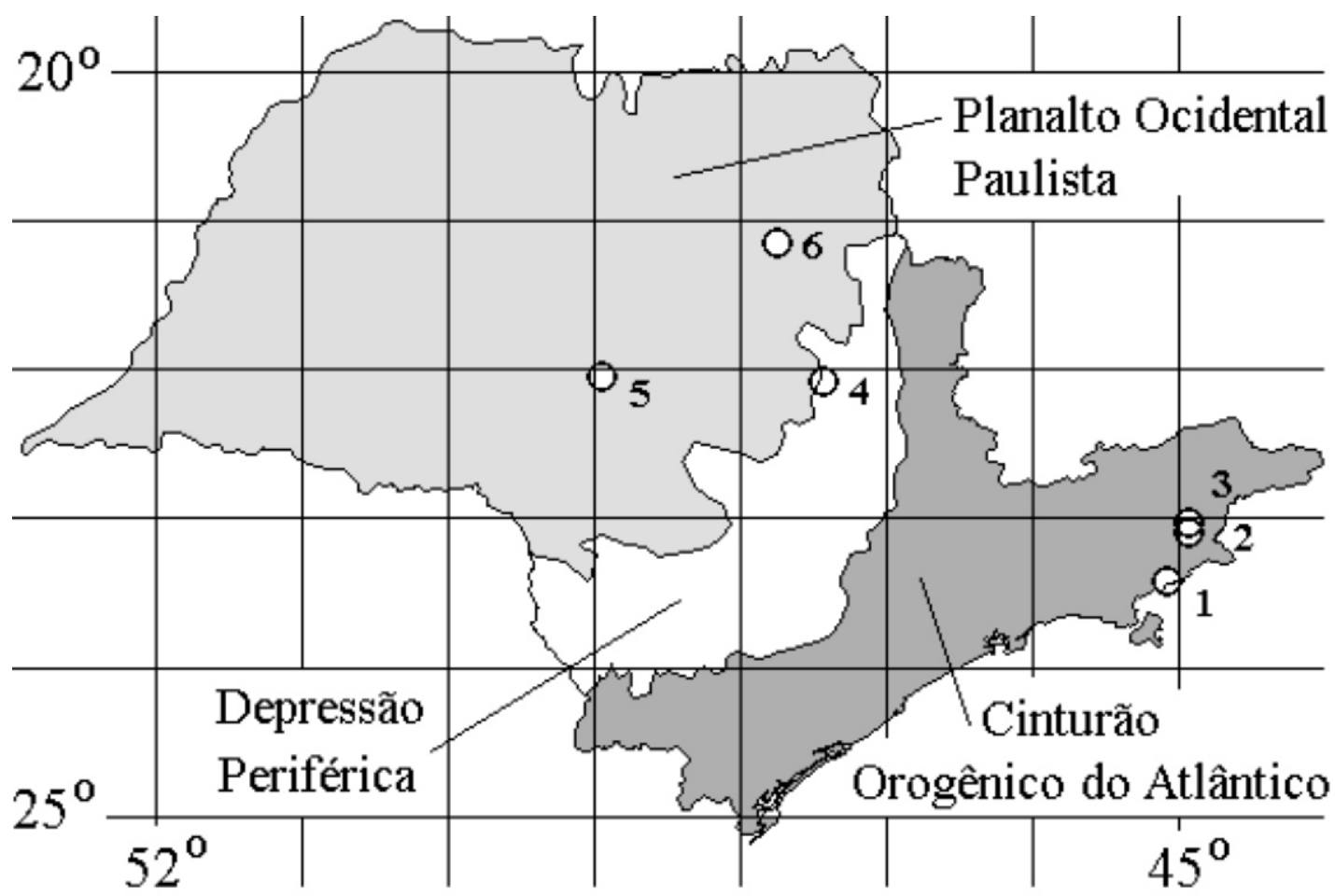

Figura 1- Localização das áreas de estudo: (1) Ubatuba; (2) Jacuí; (3) Bangu; (4) São Joaquim; (5)Soturninha e (6) Ribeirão Preto.

Os MDE testados foram elaborados por meio de krigagem das curvas de nível de mapas publicados, segundo metodologia apresentada e disponibilizada por Valeriano (2002). De acordo com este autor, o método escolhido para formação do MDE permite análise digital de feições delicadas do relevo, como forma de vertentes e dos canais de drenagem, em contraposição a métodos mais expeditos (interpolação linear, por exemplo), cuja aplicação em processos derivativos resulta em feições irreais. As especificações de georreferência e geometria dos MDE testados neste trabalho estão resumidas na Tabela 2. Nas Figuras 2 a 4 estão apresentadas uma superfície topográfica de cada área sob um processo de visualização (ADD: Azimute, Drenagem e Divisores) desenvolvido especialmente para a percepção da estrutura de hidrologia superficial e fluvial de microbacias (Valeriano, 2002). 
Tabela 2 - Especificações de georreferência e geometria das imagens formadas por interpolação dos dados topográficos

\begin{tabular}{|c|c|c|c|c|c|c|c|c|}
\hline Área & $\begin{array}{l}\text { Zona } \\
\text { UTM }\end{array}$ & $\begin{array}{l}\mathrm{X}_{\mathrm{mín}} \\
(\mathrm{mE})\end{array}$ & $\begin{array}{l}\text { Ymín } \\
(\mathrm{mN})\end{array}$ & $\begin{array}{l}\mathrm{X}_{\operatorname{máx}} \\
(\mathrm{mE})\end{array}$ & $\begin{array}{l}\text { Ymáx }_{\text {ma }} \\
(\mathrm{mN})\end{array}$ & $\begin{array}{l}\text { Resolução } \\
\text { espacial (m) }\end{array}$ & $\mathrm{n}^{\mathrm{o}}$ col. & $n^{\circ} \operatorname{lin}$. \\
\hline Soturninha & 23 & 716200 & 7558390 & 720190 & 7563380 & 10 & 400 & 500 \\
\hline São Joaquim & 22 & 239550 & 7552800 & 249730 & 7559780 & 20 & 510 & 350 \\
\hline Bangu & 22 & 509000 & 7449700 & 522980 & 7456680 & 20 & 700 & 350 \\
\hline $\begin{array}{l}\text { Grande } \\
\text { Ubatuba }\end{array}$ & 22 & 480800 & 7404800 & 492780 & 7418780 & 20 & 600 & 700 \\
\hline Jacuí & 22 & 501800 & 7434240 & 520980 & 7456220 & 20 & 960 & 1100 \\
\hline Ribeirão Preto & 22 & 195500 & 7636370 & 218270 & 7668740 & 30 & 760 & 1080 \\
\hline
\end{tabular}

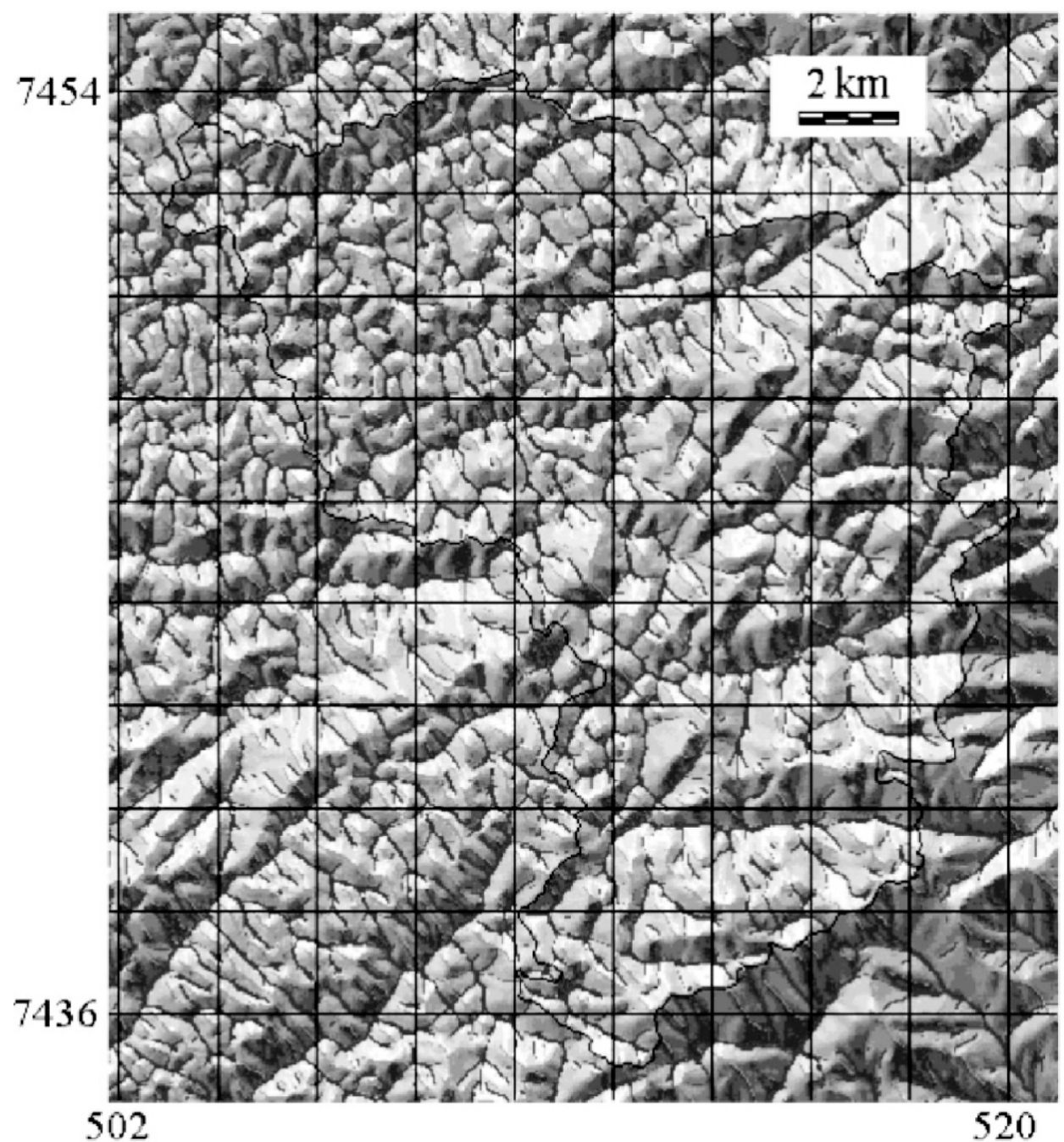

Figura 2- Superfície topográfica da microbacia rio Jacuí 17.111há. Coordenadas em 1.0000mE (x) e $1.000 \mathrm{mN}(\mathrm{y})$, com malha de $2.000 \mathrm{~m}$. 


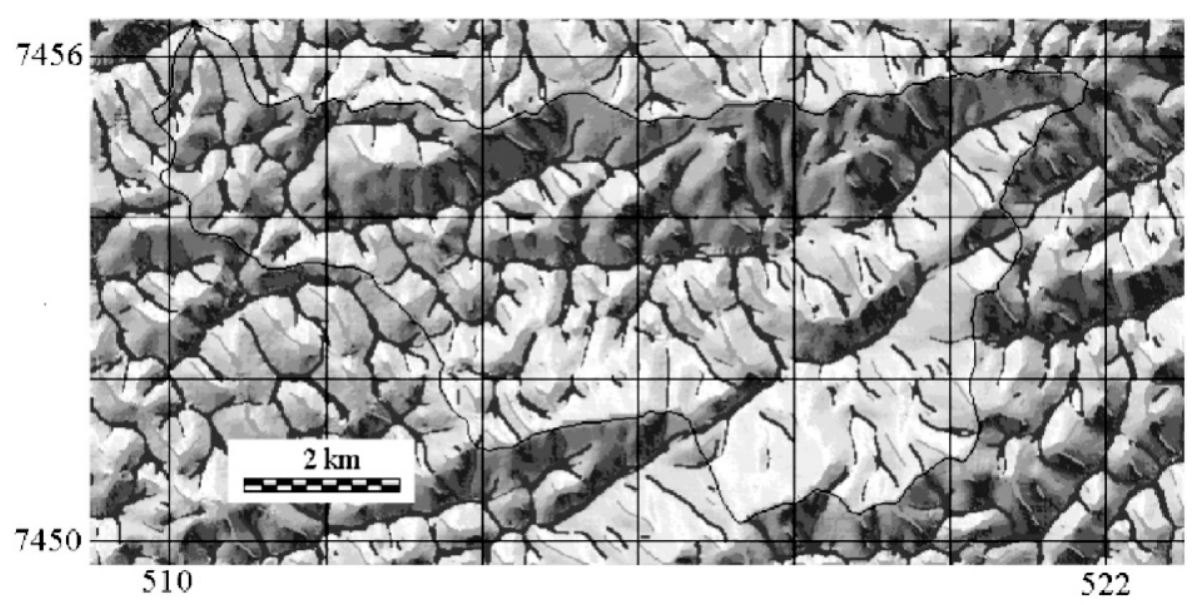

Figura 3 Superfície topográfica da microbacia do rio Bangu 4.006há. Coordenadas em 1.000Me (X) E $1.000 \mathrm{Mn}(\mathrm{y})$, com malha de $2.000 \mathrm{~m}$.
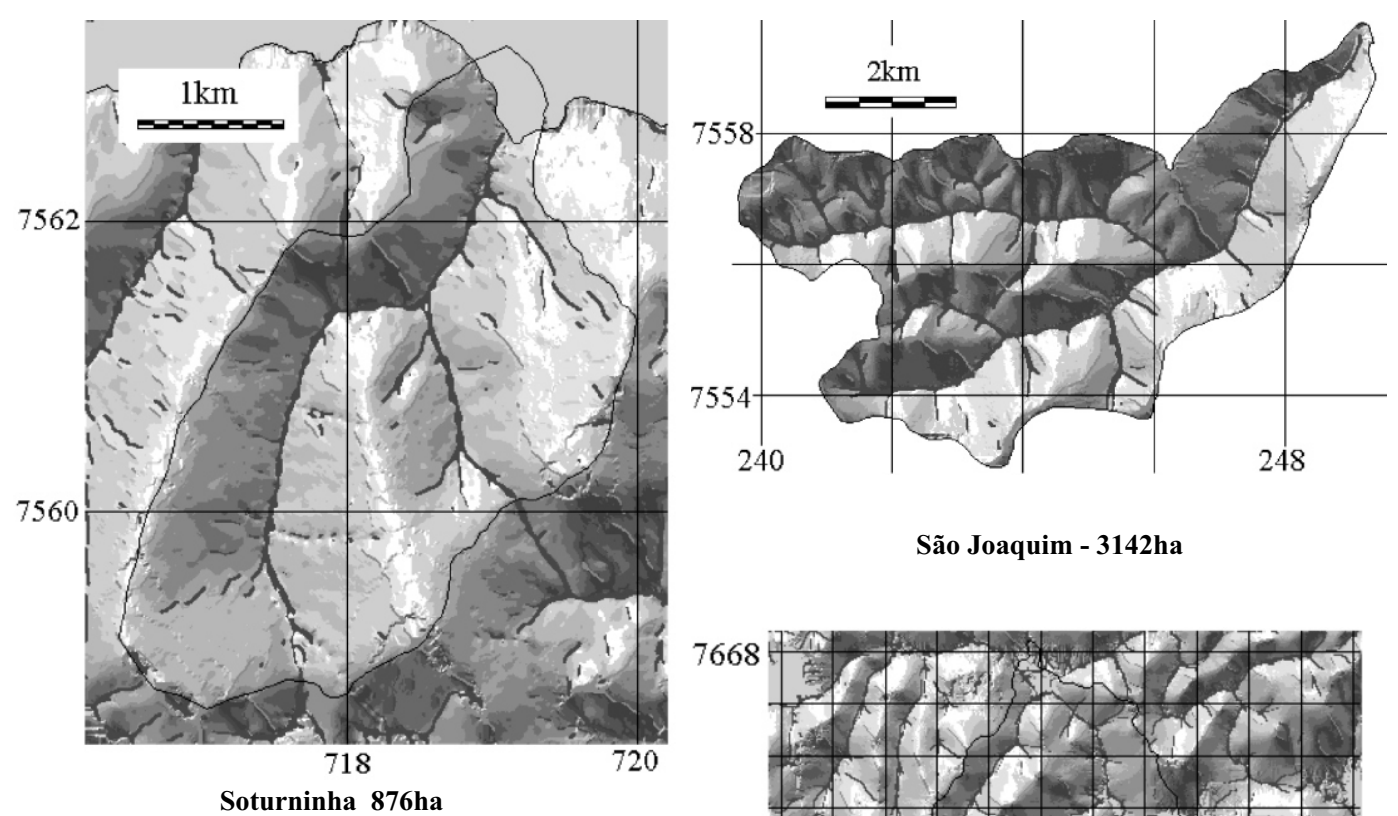

São Joaquim - 3142ha
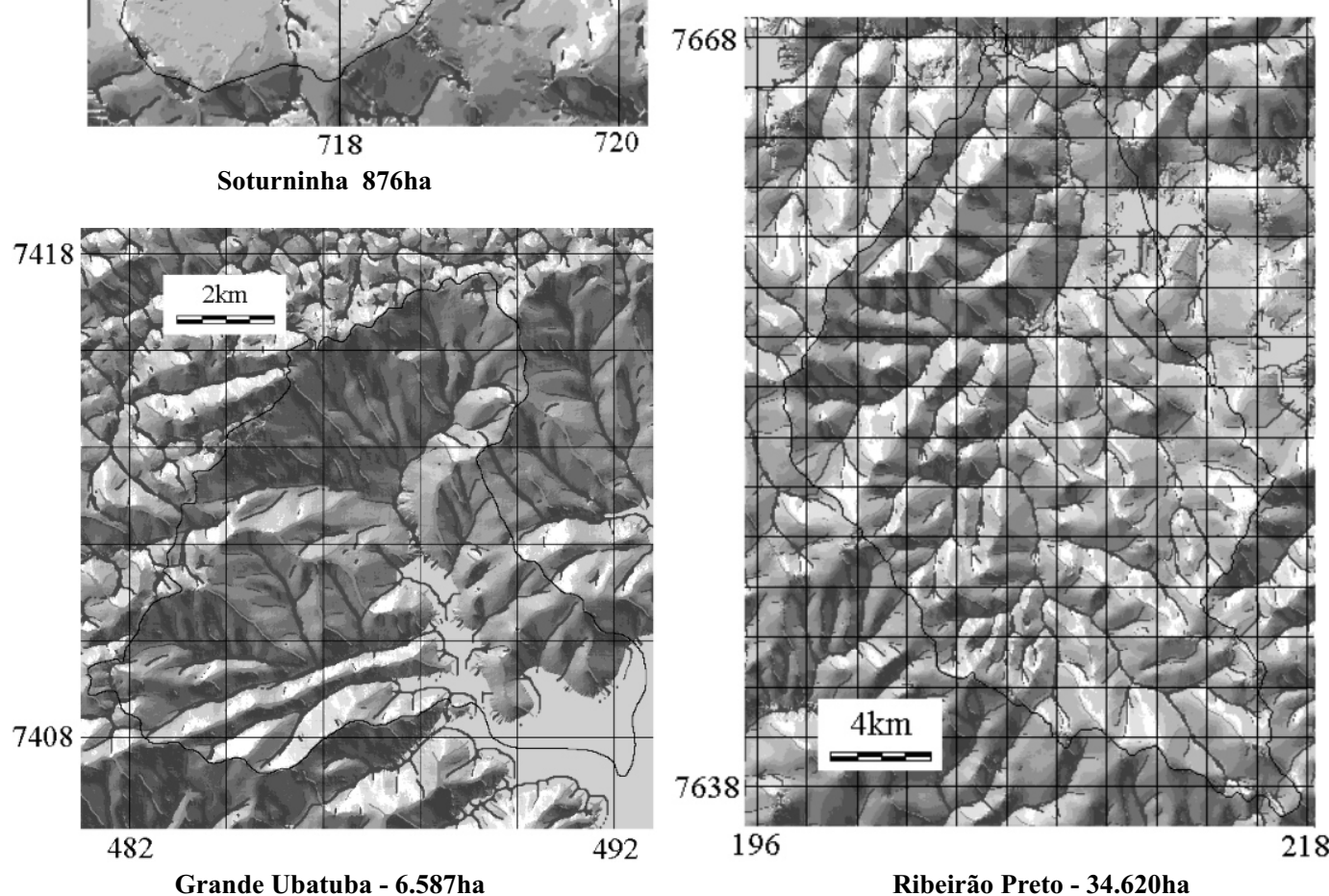

Figura 4 Superfícies topográficas das microbacias do corrégo Soturninha, córrego São Joaquim, rio Grande Ubatuba e Ribeirão Preto. Coordenadas em $1.000 \mathrm{mE}$ (x) e $1.000 \mathrm{mN}$ (y), com malha de $2.000 \mathrm{~m}$. 
Os MDE foram processados com o uso do aplicativo Idrisi (Eastman, 1995), armazenando-se os passos de processamento na linguagem de programação do mesmo (Idrisi Macro Language). Foram aplicadas janelas móveis de $3 \times 3$ pixels (nas 4 direções dos filtros da Figura 5) sobre a imagem de orientação de vertentes. Em cada posição da janela, foram subtraídos os ângulos azimutais dos lados recíprocos do pixel central, resultando num valor proporcional à curvatura horizontal em cada direção.
O resultado da operação da janela móvel é dependente da classe de orientação local, com uma relação entre a condição de curvatura (divergente/convergente) e o sinal (+/-), que se apresenta invertida para vertentes de orientações opostas (Figura 5). Tal inversão não ocorreria se fossem aplicadas 8 janelas (as 4 descritas mais suas recíprocas), porém isto significaria um custo computacional muito maior, enquanto a inversão de sinal pode ser aplicada implicitamente em outra etapa

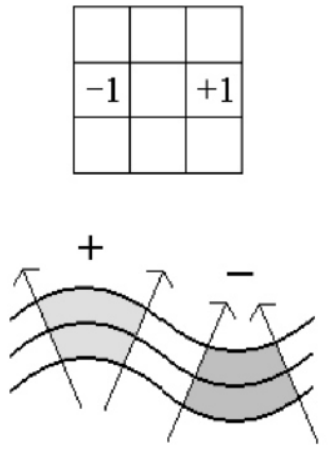

$\mathrm{N}$

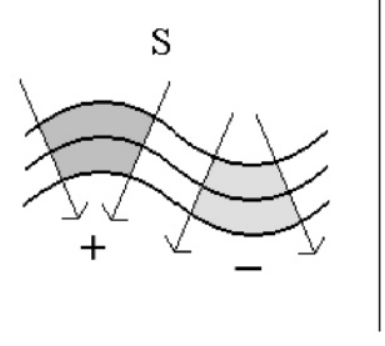

direção da água
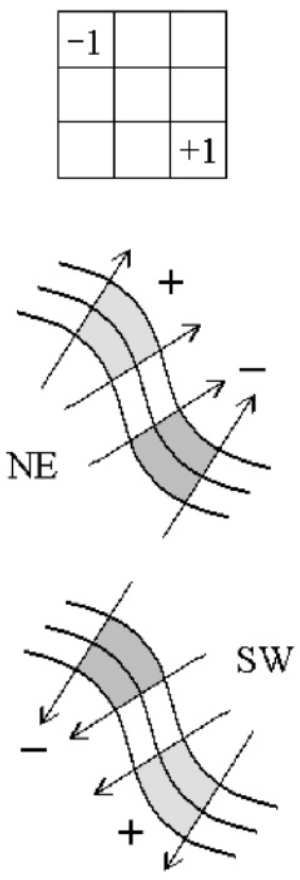

convergente
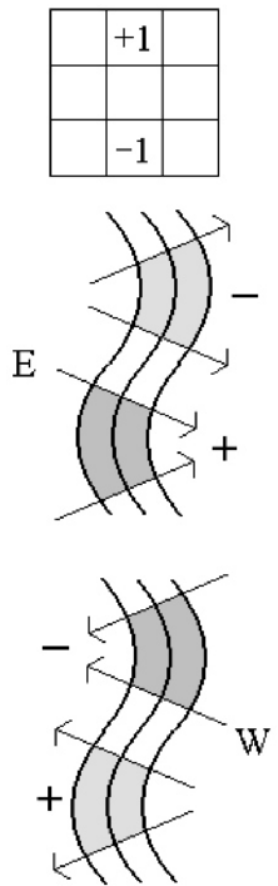

retilíneo
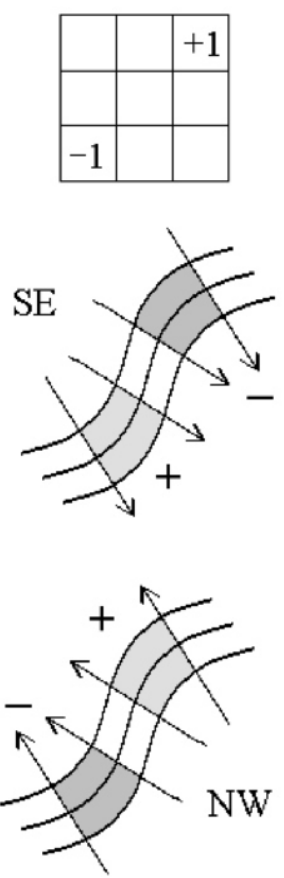

Figura 05 Aplicação das janelas móveis sobre a imagem de orientação de vertentes.

A Figura 6 apresenta o encadeamento das etapas de formação do PI de curvatura horizontal. Apenas uma das curvaturas calculadas pelas diferentes janelas representa a curvatura horizontal do pixel. O armazenamento da curvatura aplicável em cada situação numa única imagem foi coordenado por imagens booleanas $(0$ : errada; 1 : correta $)$ da classificação da orientação de vertentes em octantes. Dos octantes diametralmente opostos, um dos resultados deve ter seu sinal invertido, isto é, multiplicado por -1 (de acordo com a Figura 5) e de modo coerente entre as diferentes orientações das janelas móveis. O ângulo calculado é normalizado pela distância horizontal entre as células operadas pelas janelas móveis. Na programação das etapas, tal distância representa uma das entradas, que irá dividir as diferenças de ângulo encontradas e, para economia de processos, sua aplicação incluiu a mudança de sinal mencionada anteriormente. O resultado normalizado foi programado para estar expresso em graus por metro $(/ \mathrm{m})$, passível, portanto, de comparação entre imagens sob diferentes resoluções.

Sob a sistemática de cálculo adotada, teoricamente, vertentes retilíneas têm valor de curvatura nulo, vertentes convergentes têm valores positivos e divergentes têm curvatura negativa. Entretanto, muito pouco do que julgamos ser retilíneo apresenta curvatura rigorosamente nula, cabendo nessa interpretação uma faixa de tolerância. Além disso, imprecisões de todo o processo desde o mapeamento, passando pelo processamento digital, geram flutuações nos cálculos realizados para a 
curvatura horizontal.

Portanto, uma seqüência de testes realizados em conjunto sobre os MDE das seis microbacias foi desenvolvida para uma determinação arbitrária dos limiares para vertentes retilíneas, de modo a resultar em mapas coerentes entre si quando comparados, em relação aos tipos de relevo. Os testes consistiram da geração de mapas que foram submetidos a comparações interpretativas com as cartas topográficas e da observação em escala padronizada de perfis de vertentes representativas e excepcionais de cada área. Complementadas por descrições relatadas na literatura geomorfológica (Almeida, 1964; Ross \& Moroz, 1997), bem pelo próprio conhecimento de campo, estes testes levaram à seleção do intervalo de $-0,0380 / \mathrm{m}$ a $+0,0511 / \mathrm{m}$ para a classe de vertentes retilíneas. Valores abaixo desse intervalo foram classificados como convergentes e acima como divergentes.

Teoricamente, numa variação contínua de curvatura horizontal, haverá sempre um pouco de terreno retilíneo entre as classes convergentes e divergentes. Portanto, após a classificação, nova suavização dos resultados mostrou-se necessária para redução do número de pequenos polígonos da classe retilíneo, o que foi feito com filtro moda, que promove, entre outros efeitos, a coalescência de classes iguais que estejam próximas. Tais suavizações foram testadas sob diferentes dimensões de janela móvel buscando-se atingir um grau desejável de generalização cartográfica, até que se selecionassem janelas $7 \times 7$. Desse modo, os polígonos de terreno retilíneo devidos somente à transição entre as classes divergentes e convergentes foram em parte eliminados, restando nesta classe vertentes mais coesas.

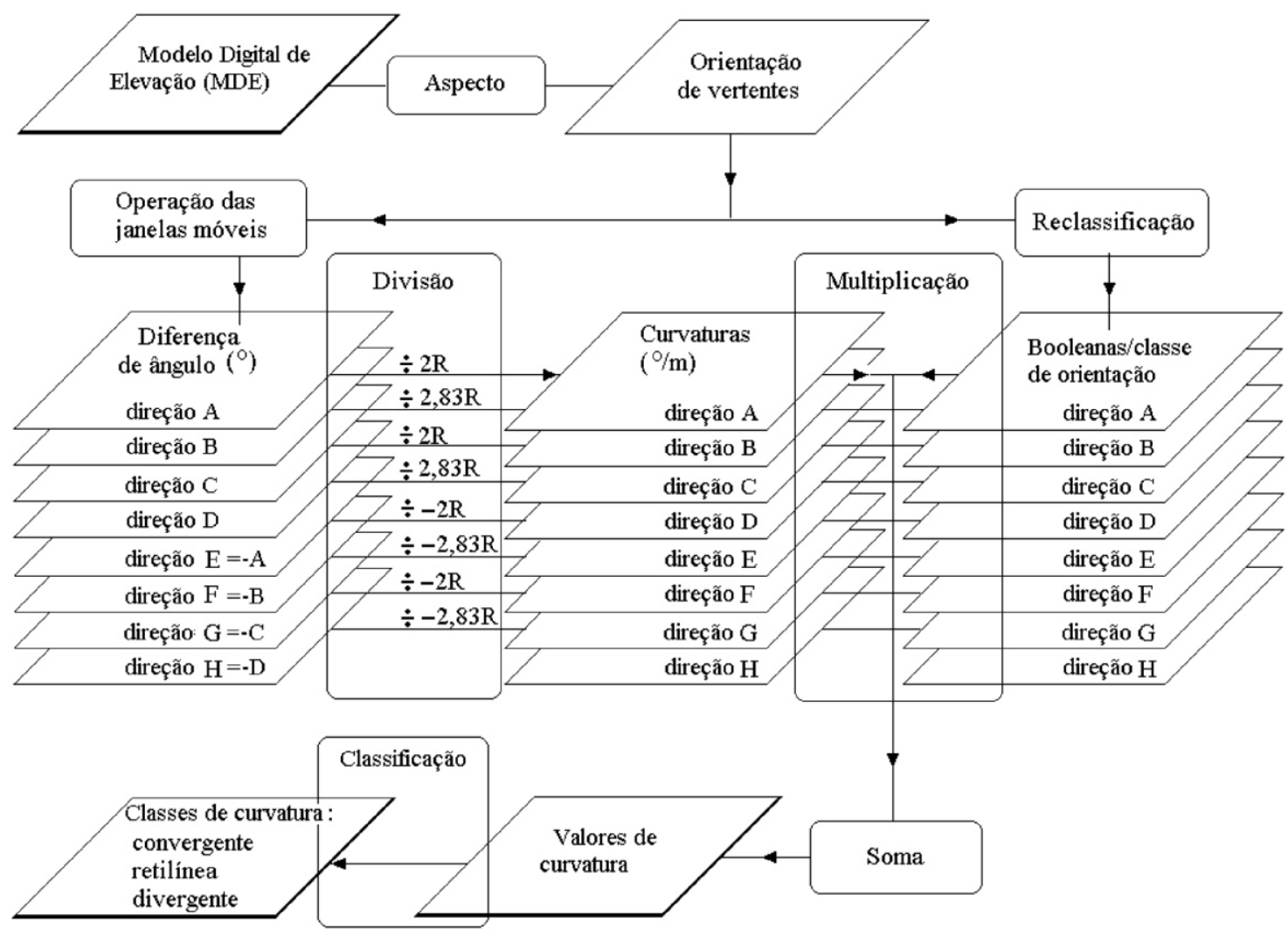

Figura 6 Processamento do MDE para o mapeamento da curvatura horizontal. R é a resolução espacial do MDE.

\section{Resultados e Discussão}

Os valores numéricos de curvatura apresentaram distribuições de freqüência distintas entre as diferentes condições de relevo (Figura 7). A diferença entre as microbacias do Cinturão Orogênico do Atlântico (Bangu, Grande Ubatuba e Jacuí) e aquelas da Bacia Sedimentar do Paraná (São Joaquim, Soturninha e Ribeirão Preto) ficou evidente pela maior dispersão geral do primeiro grupo.

A média de curvatura horizontal das microbacias mostrou-se um indicador geral ambíguo, com todos os casos em torno de zero. A média dos módulos de curvatura horizontal para cada microbacia seria um indicador menos ambíguo, em parte, porém o efeito de valores extremos sobre o cálculo fizeram esta variável caracterizar as microbacias de maneira confusa, indicando as áreas de Soturninha e Grande Ubatuba como parecidas. Da mesma forma, os valores máximos e mínimos, bem como a amplitude, não se apresentaram como bons indicadores da condição de relevo das microbacias. Estes resultados restringem a utilidade da análise de curvatura horizontal a avaliações de caráter local. 

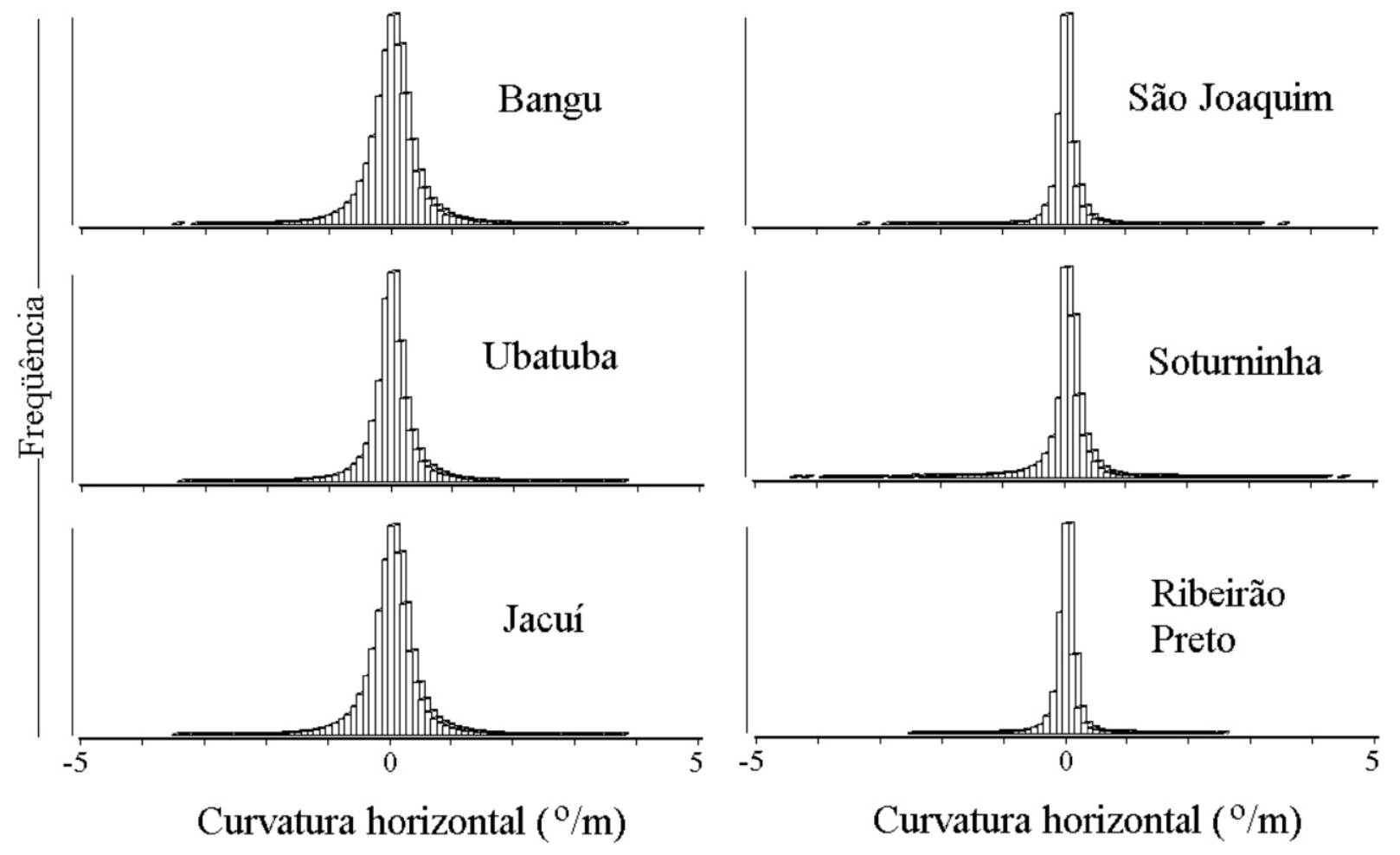

Figura 7 Histogramas da curvatura horizontal das microbacias em estudo.

Para a classificação qualitativa da curvatura vertical, limiares crescentes de tolerância em torno do valor nulo causaram um grande aumento inicial da classe de vertentes retilíneas (Figura 8) para as microbacias de relevo suave (São Joaquim, Soturninha e Ribeirão Preto). A contribuição territorial da classe retilínea nas demais microbacias tende a crescer em menor grau, devido à maior dispersão e amplitude dos valores numéricos de curvatura em relevo movimentado.

Foram observadas taxas semelhantes de modificação do território das classes côncavo e convexo na maioria dos casos, com a exceção das áreas pertencentes à Bacia Sedimentar do Paraná, sobretudo os córregos
Soturninha e São Joaquim, onde a classe de vertentes divergentes teve sua área reduzida em maior grau. Este ensaio levou à adoção de limiares assimétricos em relação à curvatura nula, selecionando-se os limites de $-0.0380 / \mathrm{m} \mathrm{e}+0.0551 / \mathrm{m}$ como o intervalo de vertentes retilíneas. Deve-se ressaltar que esta escolha foi feita de modo arbitrário, com base na apreciação visual dos mapas resultantes, de modo que a distribuição territorial das classes apresentasse um indicador diferenciado entre os tipos de relevo descritos para as microbacias.

Espera-se, no entanto, que maiores contribuições do mapeamento da curvatura horizontal estejam relacionadas aos valores numéricos do que a classes estabelecidas arbitrariamente. 


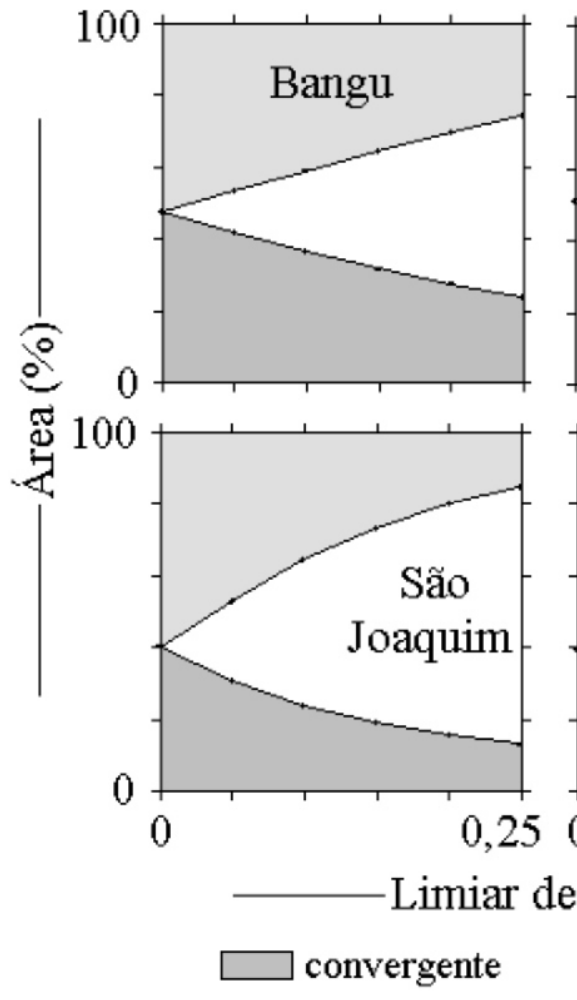

A Figura 9 apresenta um conjunto de quadrículas de mesmas dimensões ( $2 \mathrm{~km}$ de lado) das diferentes microbacias, classificadas de acordo com o limiares adotados, parte do conjunto de testes que subsidiaram a adoção deste critério. Comparando estes resultados sob escala padronizada, observa-se que os limiares adotados e procedimentos de suavização apresentaram uma flexibilidade razoável para caracterização das microbacias entre as

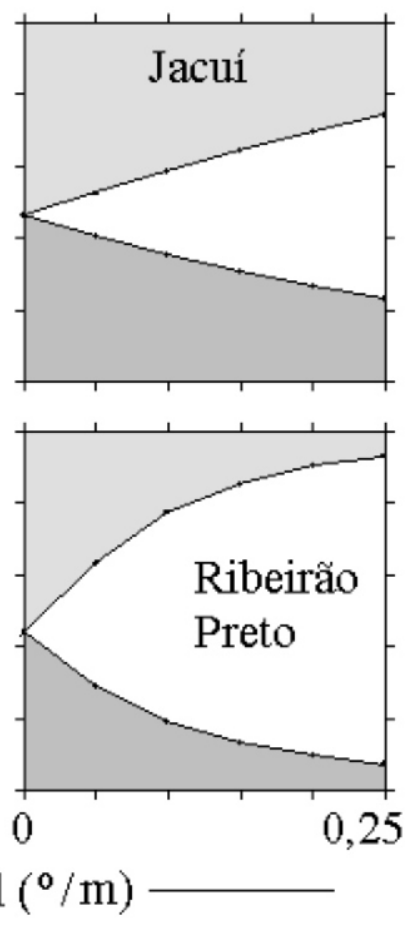

divergente diferentes situações de relevo. Além das eqüidistâncias verticais de cada mapa utilizado, as diferenças de comprimento de rampa, declividade média, toposseqüência e altura de vertentes das diversas áreas mostraram-se inócuas para cálculo digital da curvatura horizontal tal como proposto. Estes resultados indicam o potencial de informação da curvatura do MDE como uma variável independente das demais variáveis topográficas mencionadas.

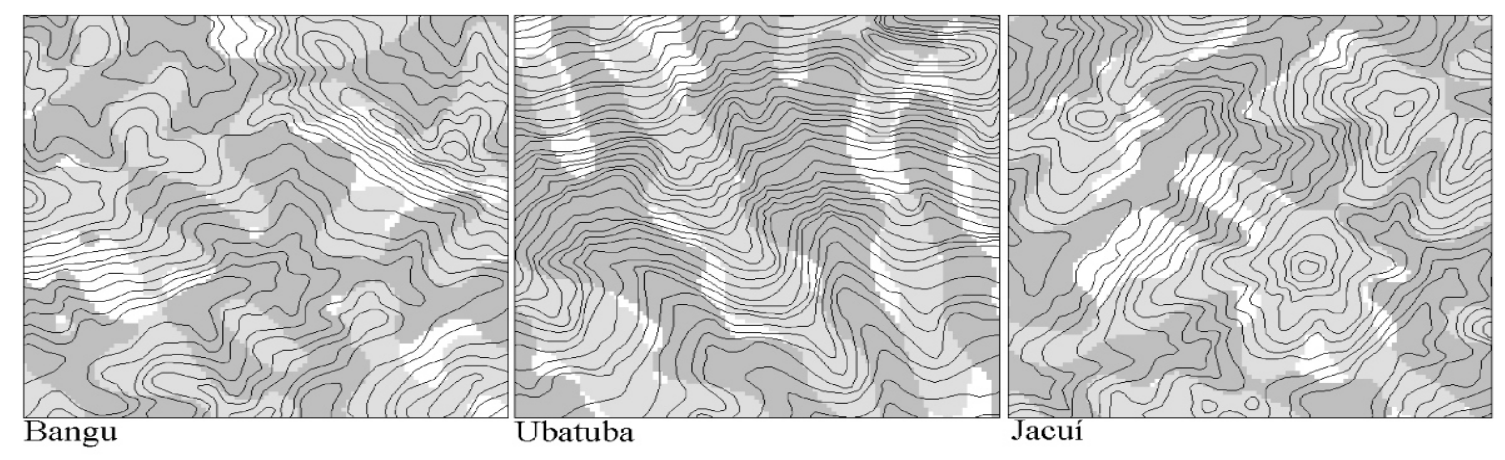

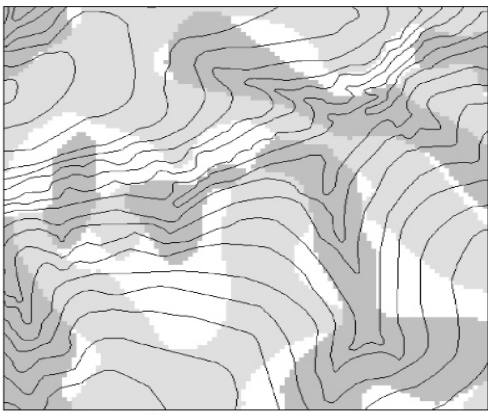

São Joaquim

$\square$ convergente
Ubatuba

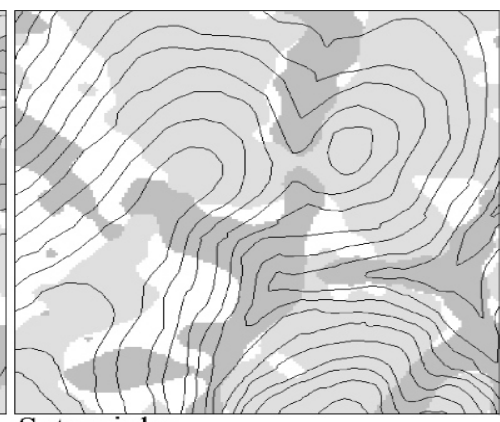

Soturninha

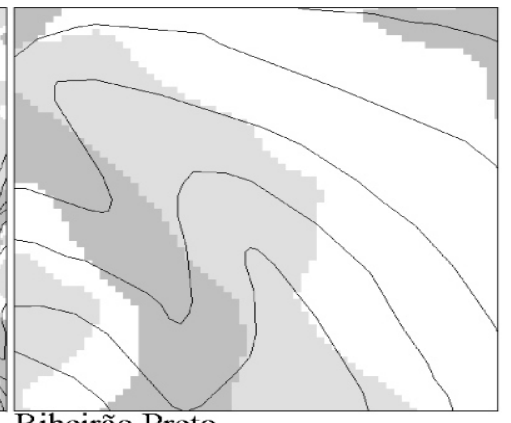

Ribeirão Preto

Figura 9 Quadrículas de mesma escala do mapeamento da curvatura horizontal das microbacias estudadas comparadas sob mesma escala. 
apresenta-se satisfatório. Nas Figuras 10 a 12 estão apresentados os mapas de classes de vertentes das microbacias estudadas.

A distribuição territorial e o padrão de seqüência das classes ao longo das vertentes mostraram-se informações interessantes para a caracterização morfométrica das diferentes microbacias.

Os mapas gerados mostraram-se coerentes com o conhecimento prévio das áreas de estudo, indicando seu potencial para a caracterização de vertentes. Áreas de relevo semelhantes mostraram padrões semelhantes de curvatura, sem efeito das diferenças de escala e de resolução.

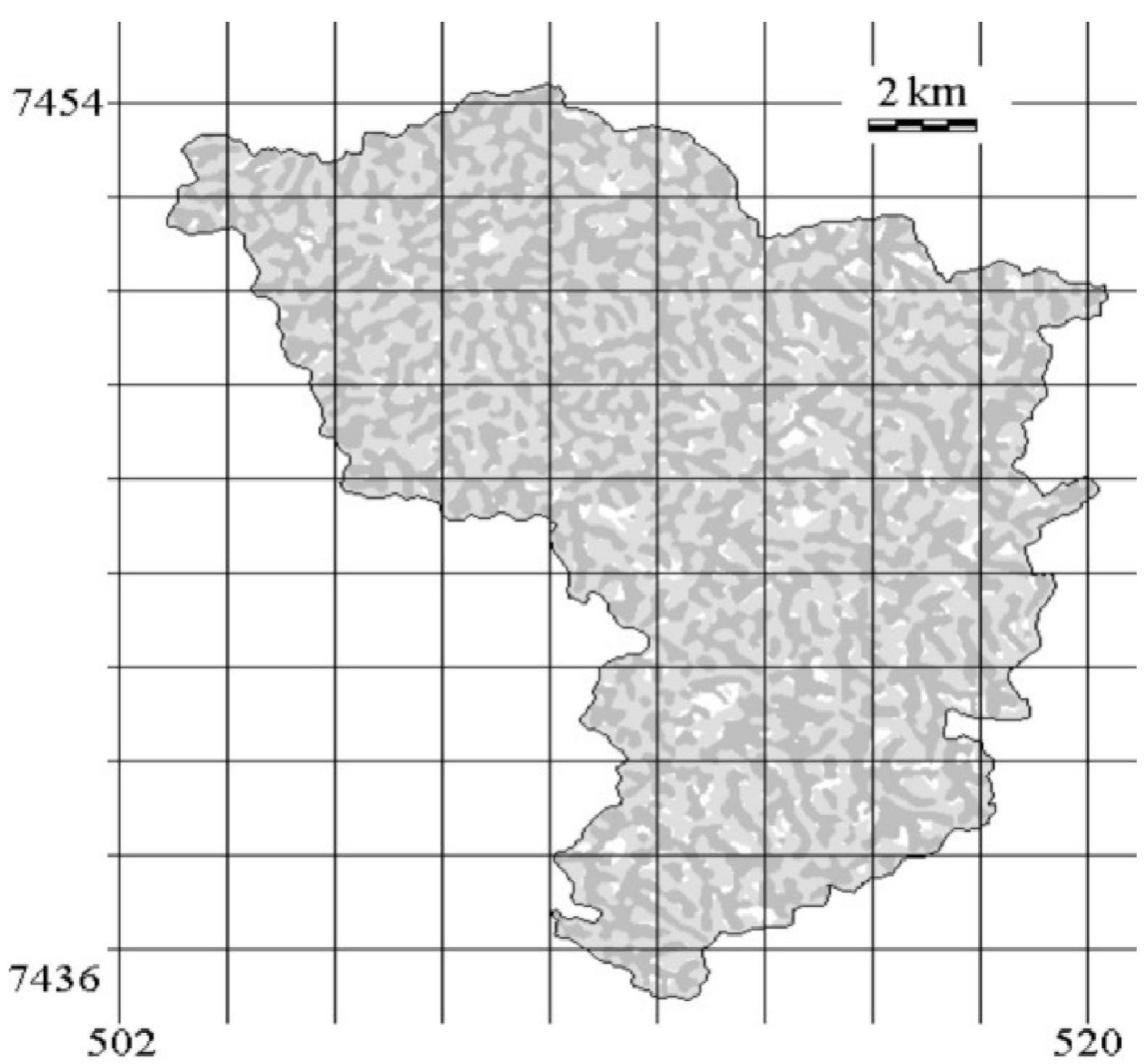

Figura 10 Mapa de classes de curvatura horizontal da microbacia rio Jacuí, de acordo com a legenda da Figura 9. 


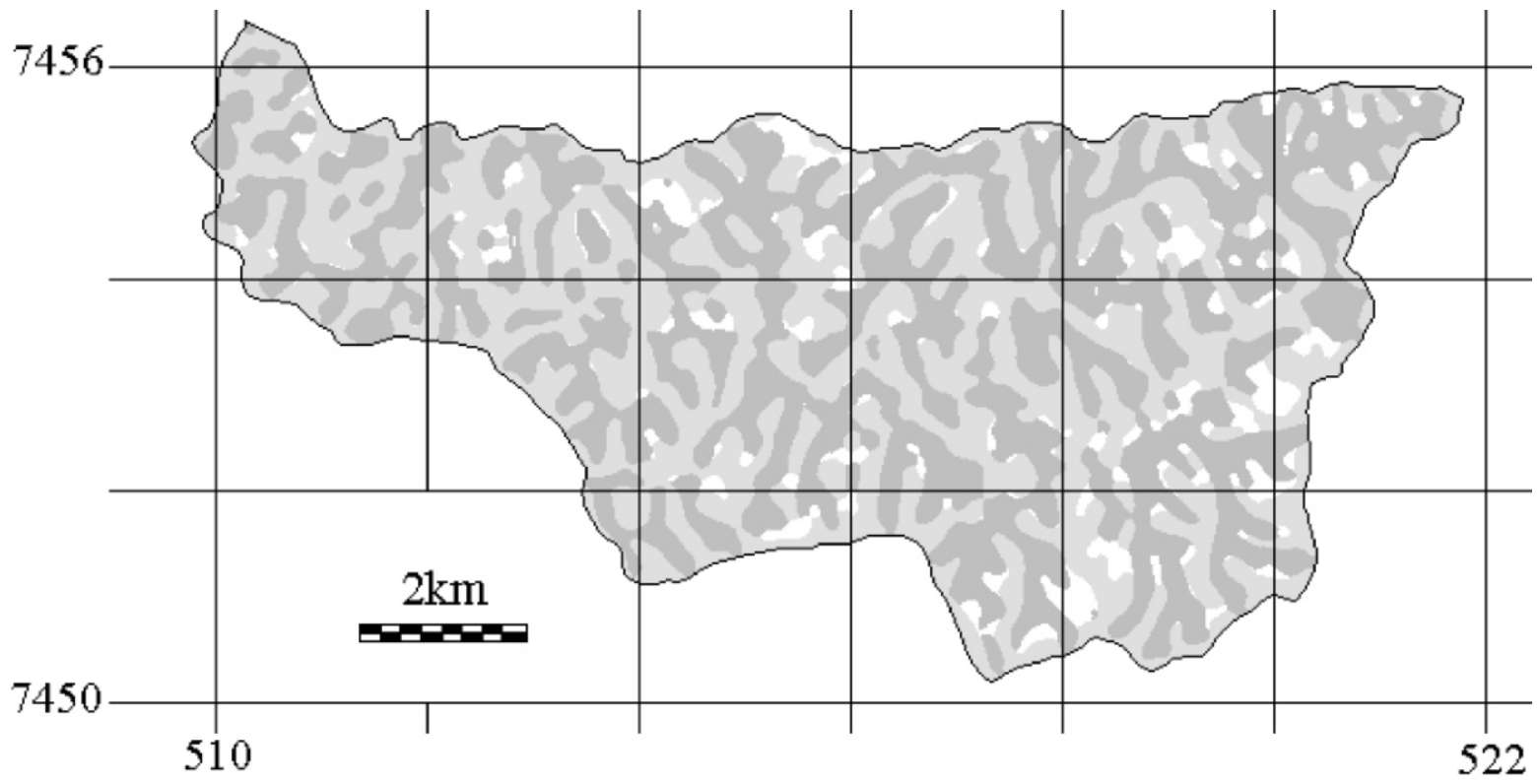

Figura 11 Mapa de classes de curvatura vertical da microbacia do rio Bangu, de acordo com a legenda da figura 9.
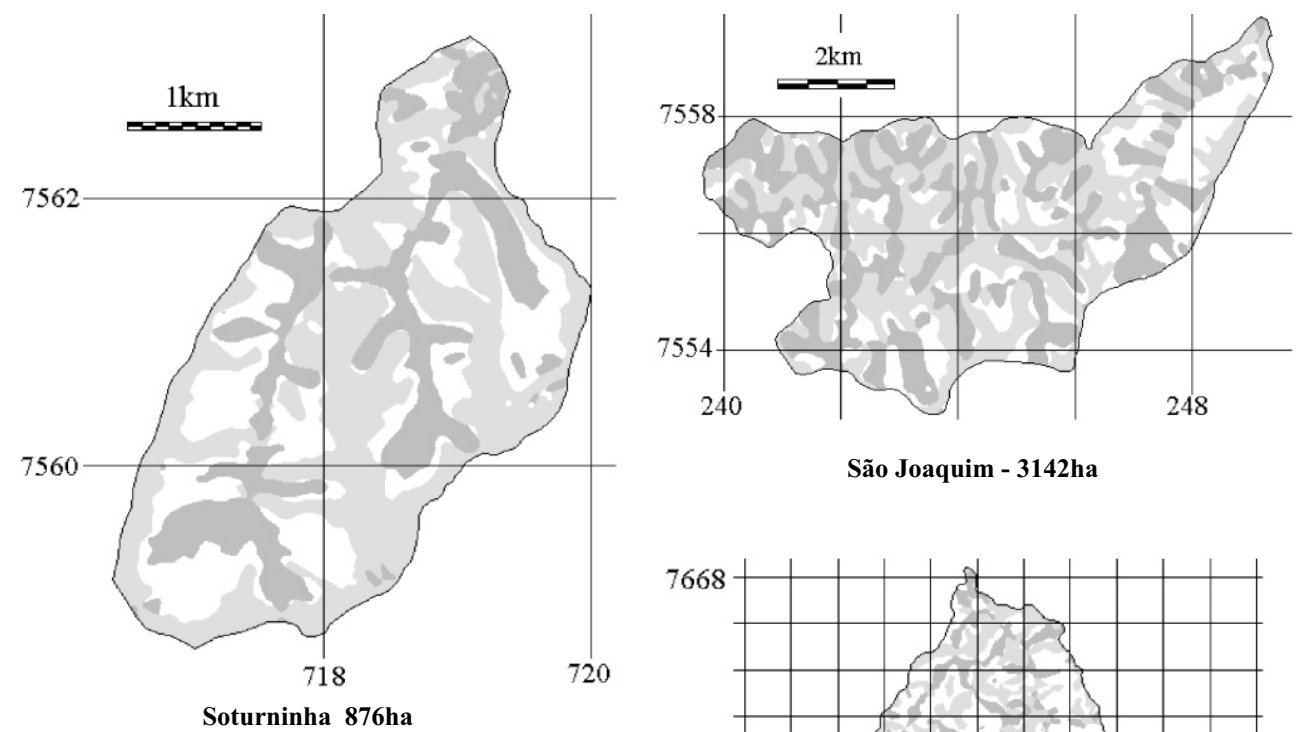

São Joaquim - 3142ha
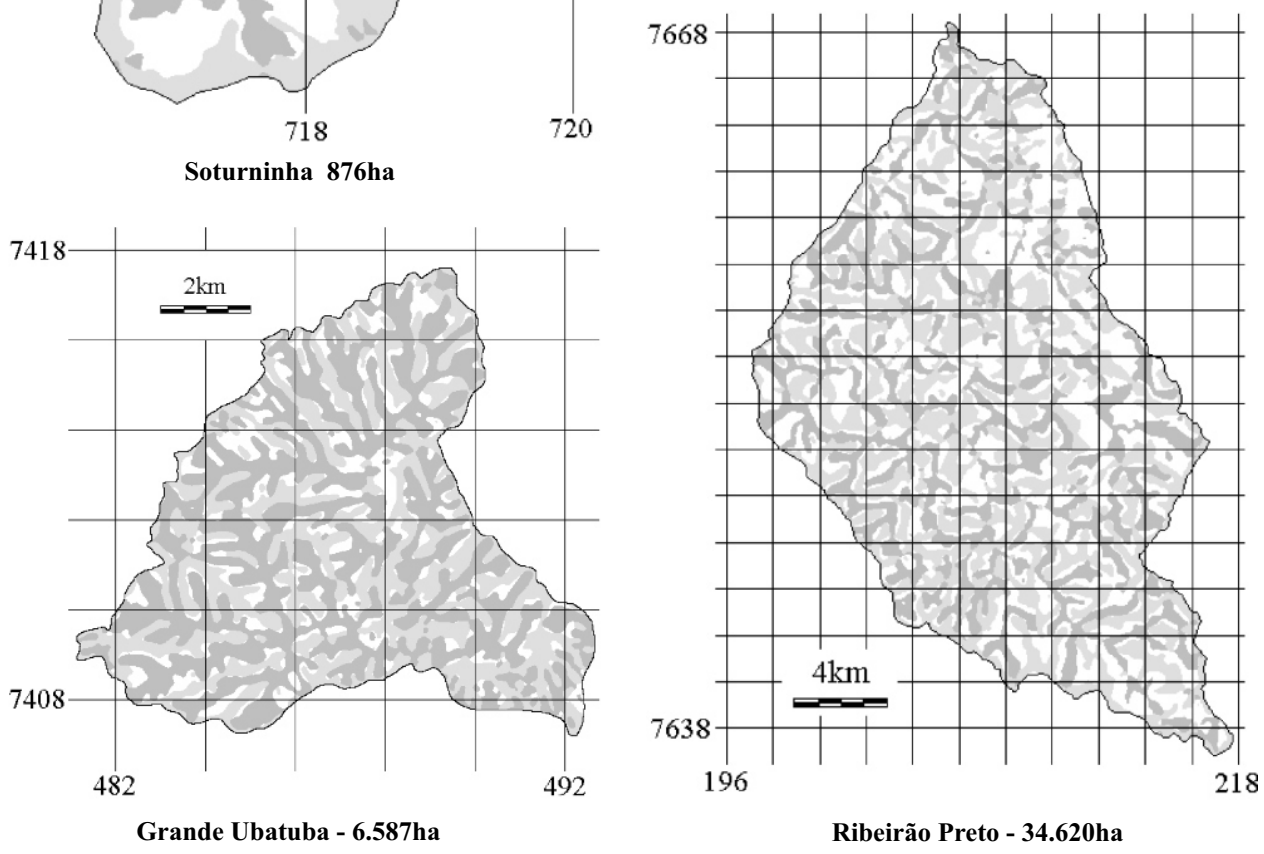

Figura 12 - Mapa de classes de curvatura vertical das microbacias do córrego Soturninha, córrego São Joaquim, rio Grande Ubatuba e Ribeirão Preto, de acordo com a legenda da Figura 9. 
A distribuição territorial das classes de segmentos de vertentes nas microbacias estudadas está apresentada na Figura 13. De modo geral, as proporções refletiram as descrições das unidades geomorfológicas (Ross \& Moroz, 1997) a que pertencem as microbacias. As microbacias pertencentes ao Cinturão Orogênico do Atlântico
(Bangu, Grande Ubatuba e Jacuí), com seu relevo movimentado, apresentam pouca área de vertentes retilíneas. Ocasionais misturas de tipos de relevo, a exemplo da observação feita para Grande Ubatuba (a presença da planície), respondem pelas discrepâncias. As demais microbacias apresentam maior porção de vertentes retilíneas.
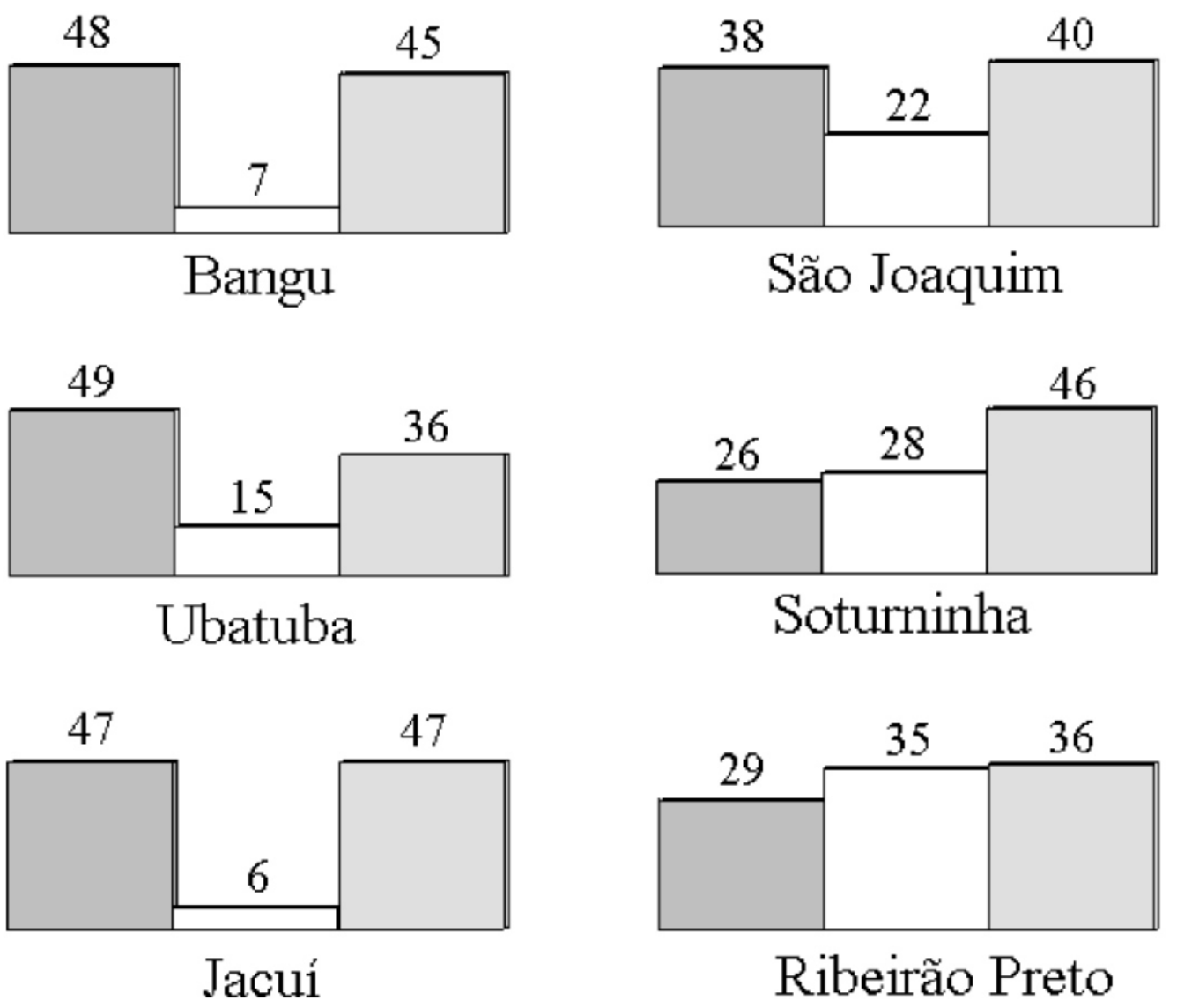

convergente

retilíneo

divergente

Figura 13 Distribuição territorial das classes de curvatura horizontal das microbacias estudadas.

\section{Conclusões}

1. Uma forma de mapeamento da curvatura horizontal de vertentes pôde ser programada para fazer análise de modelos digitais de elevação (MDE) automaticamente, com operações de aspecto e de janelas móveis, essencialmente, resultando em planos de informação numéricos expressos em diferenças de orientação de vertentes por distância horizontal $(/ \mathrm{m})$ como unidade.

2. A curvatura horizontal calculada por geoprocessamento mostrou-se flexível para o mapeamento da variável sob diferentes especificações cartográficas e do modelo digital de elevação, desde que se forneça a resolução espacial do MDE analisado.

3. O mapeamento da curvatura horizontal mostrou-se independente da declividade e do comprimento de rampa local.

4. Foi possível a adoção de limiares arbitrários de curvatura horizontal para o estabelecimento de classes de vertentes (convergentes, retilíneas e divergentes) cujas distribuições dentro e entre as microbacias se apresentassem coerentes com descrições geomorfológicas relatadas na literatura e com as verificações realizadas em comparações sob escala padronizada.

5. O mapeamento digital da curvatura vertical de vertentes apresentou potencial para a análise do relevo em caráter local que associem diferenças de atributos dos elementos da paisagem dentro de uma microbacia; as avaliações regionais de 
sua distribuição territorial mostraram-se ambíguas, com pouca capacidade de caracterização de relevos.

\section{Agradecimentos}

Este trabalho integra o projeto "Padronização de metodologias para tratamento de dados topográficos de microbacias" (processo número: 301029/00-8-NV), financiado pelo CNPq.

\section{Referências Bibliográficas}

Almeida, F. F. M. Fundamentos geológicos do relevo paulista. In: São Paulo. Instituto Geográfico e Cartográfico (ed.). Geologia do Estado de São Paulo (Boletim 41). São Paulo: IGC, 1964. cap. 2, p. 167-262.

Briggs, D. J.; Shishiro, E. K. Soil variability in geomorphologically defined survey units in the Albudeite area of Murcia Province, Spain. In: Jungerius, P. D. (ed.). Soils and Geomorphology (Catena supplement n* 6). Braunschweig: Catena Verlag, 1985. cap. 2, p.69-84.

Castro, A. G.; Valério Filho, M. Simulação da expectativa de perdas de solo em microbacia sob diferentes manejos florestais. Revista Brasileira de Ciência do Solo, v.21, n.3, p.41926, 1997.

Davis, W. M. The convex profile of badland divides. Science, v. 20, p.245, 1892.

Desmet, P. J. J.; Govers, G. A GIS procedure for automatically calculating the USLE LS factor on topographically complex landscape units. Journal of Soil and Water Conservation, v. 51, n. 5, p. 427-433, 1996.

Doornkamp, J. C; King, C. A. M. Numerical analysis in Geomorphology: An Introduction. London: Edward Arnold Ltd., 1971.372p.

Eastman, J. R. Idrisi for Windows - User's Guide. Worcester, MA: Clark University, 1995.440p.

Fernandes, N. F.; Guimarães, R. F.; Gomes, R. A. T.; Vieira, B. C.; Montgomery, D. R.; Greenberg,
H. Condicionantes geomorfológicos dos deslizamentos nas encostas: avaliação de metodologias e aplicação de modelo de previsão de áreas susceptíveis. Revista Brasileira de Geomorfologia, v.2, n.1, p. 51-71, 2001.

Florinsky, I. V.; Kuryakova, G. A. Influence of topography on some vegetation cover properties. Catena, v. 27, p. 123-141, 1996.

Gilbert, G.K. The convexity of hilltops. Journal of Geology, v. 17, n. 4, p. 344-350, 1909.

Giles, P.T.; Franklin, S.E. An automated approach to the classification of the slope units using digital data. Geomorphology, v.21, p251-264. 1998.

Kinnel, P. I. A slope length factor for applying the USLE-M to erosion in grid cells. Soil and Tillage Research, v.58, n.1, p.11-17, 2001.

Meijerink, A. M. J. Data acquisition and data capture through terrain mapping units. ITC Journal, v.1988, n. 1, p.23-44, 1988.

Molnár, D. K.; Julien, P. Y. Estimation of upland erosion using GIS. Computers and Geosciences, v.24, n.2, p.183-192, 1998.

Moore, I. D.; Gessler, P. E.; Nielsen, G. A.; Peterson, G. A. Soil attribute prediction using terrain analysis. Soil Science Society of America Journal, v. 57, n. 2, p. 443-452, 1993.

Ranieri, S. B. L.; Sparovek, G.; Souza, M. P.; Dourado Neto, D. Aplicação de índice comparativo na avaliação do risco de degradação das terras. Revista Brasileira de Ciência do Solo, v. 22, n.4,p.751-60, 1998.

Ross, J. L. S.; Moroz, I. C. Mapa Geomorfológico do Estado de São Paulo. São Paulo, SP: FFLCH/USP e IPT/FAPESP, 1997. Mapas e Relatório.

Valeriano, M. M. Modelos digitais de elevação de microbacias elaborados com krigagem. São José dos Campos: Instituto de Pesquisas Espaciais (INPE-9364-RPQ/736), 2002.54p.

Valeriano, M. M.; Garcia, G. J. The estimate of topographical variables for soil erosion modelling through geoprocessing. International Archives of Photogrammetry \& Remote Sensing. Amsterdam: ISPRS, 2000, v.33, part B, p.678-685. 